\section{Development of the zootype}

SIR - I was delighted by the concept of the "zootype" to describe animals by their common developmental pattern. Slack et al. define animals by zootype, the synapomorphy of Animalia; they tie this to Wolpert's "positional information" concept ('book' and 'map') and to Hox genes. But there is a problem, exposed as the uniformity of the zootype in the multiplicity of phylotypic stages: if the interesting thing about the zootype is that everybody's got one, why is it tied to just that stage which is so characteristically different in all animal groups?

There is an orthodox explanation, which is phase difference in the passage of information across the generations: maternal structures are required to 'read out' the zygotic genome. This was clearly seen by early embryologists. Conklin ${ }^{2}$ put it well: we are chordates because our mothers were chordate, but we have blue eyes because of our own chromosomes. Many classical embryologists believed that egg architecture produced the organism's basic structure, then mendelian genes added the details.

These classical ideas remain in today's embryology. The late-blastula $\rightarrow$ gastrulation $\rightarrow$ phylotypic stage transfers morphogenetic control from mother's organization of the oocyte (polarities, and many transcripts such as bicoid), to subsequent morphogenesis by the organized transcription of zygote genes. During this time the vast DNA information store (Wolpert's 'book'), like a magnetic tape, is set up in the differentiating embryo, laced properly into the tape player. DNA, like all information, needs context to be read out or expressed. This context (Wolpert's 'map') is maternally provided gradients, ribosome machinery and messenger RNA transcripts with their labels, and constitutes the tapeplayer of my analogy. (The biochemical 'mid-blastula' transition is when zygote nuclear genes are first transcribed; but these are only effective later, further down the Hox cascade.)

Slack et al. found the idea of a phylotypic stage in the work of Reidel and Sander, but it goes back to Conklin and Wilson. In the early $1960 \mathrm{~s}$, I found the idea of an embryological concordance within each phylum so 'obvious' that I called it the "phyletic stage" in a textbook $^{3}$. Sander and I agreed, in the late 1970 s, that "phylotypic" was a better word, different from Haeckel's discredited "phyletic". However, my historical consideration of the idea ${ }^{4}$ was already published; I credited Sander with the change ${ }^{5}$.

What is the zootype, then, and what the phylotypic stage? The zootype exposes the most common method of set- ting up animal development. Placozoa, Mesozoa and sponges are not animals, according to Slack et al., if zootype is a definition of animal. However, these genuine animals might use wax cylinders, magnetic wire or vinyl disks while the rest of us use magnetic tape. Then the zootype idea works for all animals, and different phylotypic stages are different formats: chordates, annelids and coelenterates may be compared with cassette tapes, reel-to-reel and VHS, perhaps (were ammonites Betamax?). If the zootype genuinely is when Wolpert's map is drawn - when the tape is threaded - then the phylotypic stage is the first music that is played, the theme of further development.

I believe this lyricism to be justified by the beautiful way in which Slack et al. have tied old and new embryologies together, and look forward to more biological laws of this kind.

\section{Jack Cohen}

39 Greenhill, Blackwell,

Bromsgrove,

Worcs B60 1BL, UK

SIR - Slack et al. ${ }^{1}$ propose a particular pattern of expression of the set of homologous Hox genes as the defining character (synapomorphy) for the kingdom Animalia. The expression pattern of the Hox genes, which they name zootype, controls antero-posterior spatial relationships at a particular ontogenetic stage (the phylotypic stage) among a wide range of metazoan taxa. But their claim that this is the defining character for the Animalia is not substantiated. The phylotypic stage at which this pattern is expressed is indeed likely to be fundamental to animal evolution, but there are already other candidate characters for animal synapomorphy. The possession of collagen genes, for example, is clearly just as necessary for animal survival and morphogenesis $^{6,7}$. Systems that provide polarity during development will be important, but is the antero-posterior axis more fundamental than the dorsoventral axis?

We can anticipate the discovery of similarly widespread mechanisms determining other morphological features. There are several animal synapomorphies, but Slack et al. give no evidence to suggest that their zootype represents the key innovation of animal development which allowed the rapid radiation of the group and might warrant its special status as "the defining character". Indeed, it is unclear whether any morphological innovation is necessarily the key to the radiation of the Animalia. We believe a more fruitful approach would be to examine the relationships among all potential synapomorphies cladistically, across a broad range of metazoan and non-metazoan taxa. Thus, which synapomorphies, if any, hold the special status of key innovations will be identified, and we may then understand what makes an animal an animal or, indeed, what makes an animal an iguana.

\section{Nigel C. Hughes}

Department of Paleobiology,

National Museum of Natural History,

Smithsonian Institution,

Washington, DC 20560, USA

Simon M. Hughes

MRC Muscle and Cell Motility Unit and

Developmental Biology Research

Centre,

King's College London,

26-29 Drury Lane,

London WC2B 5RL, UK

SLACK ET AL. REPLY - We were aware of Cohen's use of the term 'phyletic stage' but felt that, for vertebrates at least, he was considering a stage that was earlier than what we now regard as the phylotypic stage. He nominated the neurula as the phyletic stage of vertebrates and suggested that this was the first stage controlled by zygotic as opposed to maternal messenger RNA. We consider the neurula to be earlier than the phylotypic stage for three reasons: major morphogenetic movements are still going on; it does not yet display all major body parts as cell condensations; and it precedes the stage of maximum morphological resemblance between vertebrate classes. In invertebrate embryos as well, the onset of zygotic gene activity normally occurs well before the phylotypic stage.

Of course Cohen is right that there must be, at some point in the developmental programme, elements that connect the common plan of the zootype with the body plans of individual phyla. These will presumably lie among the genes controlled by the zootype genes, and we feel that the unravelling of these steps should now be high on the agenda of taxonomic research.

With regard to the Hughes's point about collagen, we would not dispute that there may be other characters common to some or all animals, but we do think that the developmental programme is more fundamental than having one particular type of molecule. Because our

1. Slack, J. M. W., Holland, P. W. H. \& Graham, C. F. Nature 361, 490-492 (1993)

2. Conklin, E. G. Heredity and Environment in the Development of Men 184 (Princeton University Press. 1918).

3. Cohen, J. Living Embryos (Pergamon, Oxford, 1963 : 1967; 1981).

4. Cohen, J. in Maternal Effects in Development, 4th Symp. Br. Soc. Dev. Biol. (eds Newth. D. R. \& Balls, M.) 1-28 (Cambridge University Press, 1979).

5. Cohen, J. in Metamorphosis 8th Symp. Br. Soc. Dev. Biol. (eds Balls, M. \& Bownes, M.) 1-19 (Clarendon. Oxford, 1985)

6. Adams, E. Science 202, 591-598 (1978)

7. Towe, K. M. Life in the Universe (ed. Billingham, J.) 297-306 (MIT, Cambridge, Massachusetts, 1981). 